Martinho da Silva, I., Fernandes, C.O., Castiglione, B., \& Costa, L. (2016). Characteristics and motivations of potential users of urban allotment gardens: The case of Vila Nova de Gaia municipal network of urban allotment gardens. Urban Forestry \& Urban Greening, 20(1), 56-64. https://doi.org/10.1016/j.ufug.2016.07.014

\title{
Characteristics and motivations of the potential users of the Municipal Network of Urban Allotment Gardens of Vila Nova de Gaia (Portugal)
}

\begin{abstract}
Demand for urban allotment plots has recently increased in Portugal but little is known about the characteristics and motivations of the demanding population, and if and how its characteristics affect its motivations.

In this article, we use the Municipal Network of Urban Allotment Gardens (MNUAG) ${ }^{1}$ launched by the Portuguese municipality of Vila Nova de Gaia for an exploratory Case Study research. Based on the data collected in the MNUAG application forms submitted in the period 2012-2013, we describe the characteristics and the motivations of the population demanding for urban allotment gardens $(\mathrm{UAG})^{2}$ and run a Logit model to find if and how the motivations are influenced by the characteristics.

The population of applicants to the MNUAG is quite diverse. It has a balanced gender distribution and an average age of 47 years. Most of the applicants are between 25 and 64 years old, and belong to households with 2 to 4 members.
\end{abstract}

To supplement family budget, occupation of leisure times, and access to organic farming are its most important motivations, followed by environmental concerns, the practice of physical exercise, and education.

Motivations are influenced by the characteristics. This study has identified two groups of applicants with contrasting motivations. Food security is the only significant motivation for the unemployed and low-income applicants. Food safety, health concerns, environmental concerns, recreation, and education are common and frequent motivations among the upper and intermediate professional groups.

Results can have future implications on the MNUAG, namely on the UAG location and typology, plot number, and plot size. To meet the demand of all the types of applicants, while

\footnotetext{
${ }^{1}$ MNUAG - Municipal Network of Urban Allotment Gardens

${ }^{2}$ UAG - Urban Allotment Gardens
} 
fostering social cohesion, the municipality should reinforce its current small UAG structure and add to the MNUAG one or two productive parks.

Keywords: Case study research; Food safety; Food security; Logit model; Recreation; Urban gardening

\section{Introduction}

According to the United Nations (2014), world population exceeded 7 billion on March 12, 2012. More than one-half live in urban areas with limited or no access to agricultural land (European Environmental Agency, 2015). In this context, UAG constitute, to millions of city's inhabitants, the only opportunity to engage with activities related with gardening and cultivation.

UAG are not a new phenomenon in urban areas. The movement began to gain momentum worldwide with the Industrial Revolution and continued to gain strength over the years in many countries, especially in times of war and economic crisis.

In Portugal, the first UAG arose as a consequence of the rural exodus of the 1950's and 1960's. This large-scale migration to the urban areas located in the littoral, especially Lisbon, caused the construction of many new neighborhoods and several 'urban areas of spontaneous occupation'. The lack of green spaces in the newly created urban areas together with the rural background of its inhabitants led to the creation of many illegal allotment gardens or 'allotment gardens of spontaneous occupation', as they are currently designated. According to data of the municipality of Lisbon, in 1967 there were about 128 hectares of UAG in Lisbon. This number rose to about 301 hectares in 1987. To this increase contributed largely migrants from the former Portuguese colonies in Africa.

Until recently, most of the Portuguese urban population disliked UAG, as they have been associated with social inferiority and non-integration in the urban lifestyle (Martinho da Silva, 2014). This attitude has been changing since the advent of the planned UAG in the country. 
According to Gonçalves (2014), in 2013 there were 107 legal and planned urban allotment gardens in Portugal, distributed by 16 of its 18 mainland districts. The first planned UAG were promoted in 2003 by LIPOR, an inter-municipal entity responsible for managing the waste in eight municipalities of the Porto Metropolitan Area. LIPOR's program of organic urban allotment gardens (Horta à Porta) puts a great deal of emphasis on waste management through the promotion of domestic composting. Currently, it encompasses forty-five UAG, distributed by the eight counties (LIPOR, 2016).

After Porto, Lisboa is the Portuguese district with a higher number of urban allotment gardens - 15 UAG in 2014. The first UAG of this district were created between 2009 and 2011 in the county of Cascais (Gonçalves, 2014). In 2007, the Lisboa municipality launched the Horticultural Parks Project (Projeto dos Parques Hortícolas), a program dedicated to the construction of multifunctional gardens or parks with areas dedicated to urban gardening. The first two Lisboa horticultural parks were inaugurated in 2011. In 2014, the city had ten Horticultural Parks with about 400 plots in 2014 (CML, 2016).

\section{Motivations to participate in $U A G$ - Background}

Motivations to engage in UAG have been changing over the years (Armstrong, 2000). UAG started as a movement to increase food supplies in response to scarcity. But motivations have expanded far beyond the initial food security concerns and presently include food safety, environmental and health concerns, recreation, education, and social cohesion, among others (Golden, 2013).

There are two types of motivations to be engaged in UAG: the initial motivations and the secondary or unexpected motivations. The initial motivations are the ones that lead people to get involved in an UAG for the first time. The secondary motivations are the ones arising from the experience itself. Growing food is often the initial motivation to join an UAG, but awareness of its therapeutic effects or recreation potential can work as secondary motivations to keep gardeners involved in the project (Henryks, 2011).

Many authors suggest that food production is one of the most important motivations to participate in UAG (Irvine et al, 2007; Alaimo et al, 2008; Corrigan, 2011a; Kelly, 2012) as, in some cases, it can provide an important complement to household income (Holland, 2011; 
Guitart et al, 2012). Some gardeners are even willing to walk long distances to grow food motivated to eat cheap (Ilyniak et al, 2013). However, food production does not arise only by food security motivations but also as a response to growing concerns over food safety. People want to be able to consume natural, fresh and trustable food in order to supply part of their nutritional needs (Meenar, 2012).

Personal wellbeing is since long referred as a powerful motivation to participate in UAG (Kaplan, 1973; Kaplan and Kaplan, 1990). Personal wellbeing and other therapeutic effects as well as direct health benefits (Van den Berg, 2009) can be associated with the sense of accomplishment resulting from the gardening activities (Blair et al., 1991; Glover, 2003). In this range of motivations the enjoyment of nature (Clayton, 2007) is often mentioned relating the connection with nature with an increasing sense of spirituality (Kingsley et al, 2009).

Other relevant motivations are recreation and exercise (Corrigan, 2011b; Holland, 2011). Gardeners also find in their plots a space where they can develop their individual creativity in a way not possible in other aspects of their urban life (Domene and Sauri, 2006).

Education, training and the development of skills are motivations that began to be more frequently mentioned (Augustina et al., 2011, Bendt et al., 2012), highlighting the importance of engaging the youngest members of the community in positive activities. According to Meenar (2012), the development of skills can be associated with better conditions to find a job. However, few authors referred employment and business or job opportunities as a motivation to be involved in UAG (Irvine et al, 2007; Holland, 2011).

Important social motivations to engage in UAG are the opportunity for social interaction (Ilyniak et al, 2013) and the possibility to develop a sense of belonging (Guitart et al, 2012; Kelly, 2012). Glover (2003) claims that UAG 'are often more about the community than they are about gardening. They offer places where people can gather, network, and identify together as residents of a neighborhood.' UAG can also play an important role in migrants' adaptation to a new country or place, namely by providing a space where they can preserve and share their cultural identity (Baker, 2004; Teig et al, 2009; Augustina et al, 2011).

Motivations are often connected and most gardeners have more than one purpose to engage in UAG. Holland (2011) found links between education, health, food provision and leisure; 
area protection, community development and leisure; skills and training; and health and community development. While the literature generally indicates food production as the main motivation to engage in UAG, in some situations it appears that what is grown is secondary to what else is achieved (Scheromm, 2015).

Finally, there are also some reasons that negatively affect the motivation to participate in UAG: difficult access (Holland, 2011), theft and vandalism (Ilinyak et al, 2009; Teig et al, 2009), racism, and lack of time or availability to devote to the garden (Meenar, 2012).

Broadly, there is a lack of characterization of the populations using UAG in all the studies. Usually the nationalities of the gardeners are referred but there is little information about their employment, age, and other characteristics. They are often characterized in a general way, for example as 'populations of low income houses' or 'immigrants' or just 'residents of the neighborhood'. Also, the literature seldom explores if and how the characteristics of the gardeners affect their motivations to engage in urban gardening.

This paper intends to identify the characteristics and the motivations of the population applying for urban allotment gardens in Portugal, by exploring the following research questions: i) What are the main characteristics of the population applying to urban allotment gardens? ii) What motivations lead urbanites to apply to urban allotment gardens? and iii) Do the characteristics of the potential urban gardeners influence their motivations, and how?

These questions were addressed resorting to an exploratory research and taking as case study the Municipal Network of Urban Allotment Gardens (MNUAG) recently launched by the Portuguese municipality of Vila Nova de Gaia, a county located in the Porto Metropolitan Area, northwest Portugal.

\section{Material and methods}

The Case Study research methodology

This research follows the Case Study research methodology. According to Yin (2013), the Case Study research methodology can focus on one or more cases and it may be used with various purposes such as to provide descriptions, to test theory or to build theory. The option 
by this methodology in this study is justified by the lack of data on Portuguese urban gardeners' characteristics and motivations and by the exploratory character of the analysis.

\section{The MNUAG case study}

Vila Nova de Gaia is a municipality located in the Northwest of Portugal, belonging to the Porto Metropolitan Area. Its territory is bordered at west by the Atlantic Ocean, and at North and Northeast by the river Douro (Fig.1).

\section{Insert Fig. 1}

Although Vila Nova de Gaia is the most populated municipality in the Porto Metropolitan Area, with 302298 inhabitants (INE, 2012), and the third most populated in the country, after Lisboa and Sintra (INE, 2012), it had no urban allotment gardening policy until 2012. Apart from vegetable gardens of spontaneous occupation, there were only four urban allotment gardens with a total of 78 plots in the county. Awareness of this short offer, of its residents demand for cultivation plots in UAG of neighboring counties, and of the growing strategic and political importance of urban gardening, led the municipality to launch, in 2012, the MNUAG.

Most MNUAG gardens are installed in municipal lands acquired through urbanization processes. The Vila Nova de Gaia municipal master plan establishes that, for each household built, $63 \mathrm{~m} 2$ of land must be ceded for the construction of public infrastructures, services and green areas. The lack of budget to meet this requirement has led ceded lands to become expectant lands, with no defined function or use, and a maintenance cost of 1.77 euros per $\mathrm{m} 2$, once or twice a year (Silva, 2013). The installation of UAG in ceded lands brings several benefits as it avoids the cost of land acquisition for the construction of the UAG, it transfers the maintenance costs to gardeners, and it makes these lands available to the community by giving it a function (Martinho da Silva, 2014).

The MNUAG also includes UAG installed in lands ceded by privates against exemption from the obligation to keep them clean, and UAG from the initiative of companies (Silva, 2013). 
MNUAG gardens are built by the municipality and managed by the parishes or by the municipality. The plot size is established by the managing entity, according to its goals and priorities. The usual size is $50 \mathrm{~m} 2$. Managing entities with a high plot demand may require smaller plots to meet all of their requests, while managing entities with a high number of unemployed may ask for larger plots to allow urban gardeners to commercialize their products.

Anyone living or working in the municipality can apply for a MNUAG plot. Candidates should fill an application form and submit it online or handle it in their parish of residence or work. While other criteria might be established by the managing entity, plots are usually distributed according to the application order.

The gardeners cultivate the plot during the established period of time, against the signature of an agreement and the payment of 3 euros per month. Agreements are valid for one year and can be automatically renewed. They include a set of rules that include attending a course in sustainable farming and composting, using only sustainable agriculture practices, producing and using compost, separating and disposing of solid waste in proper containers, maintaining a clean and safe plot, and following the rules regarding use of the plot and common spaces (MVNG, 2013). Failure to comply with the rules might result in the termination of the agreement.

\section{The data}

The data come from the MNUAG application forms submitted in the period 2012-2013 and comprises 873 observations.

Application forms require the applicants to state their name, gender, age, address, phone and email contact, national id number, parish of residence, profession, professional situation, household size, parish of application, and motivations behind the application (initial motivations). Most questions are open-ended. Professional situation and motivations are precoded. For professional situation, applicants can chose among employed, unemployed, retired, student, and other, with the opportunity of revealing the choice 'other'. For motivations, applicants can tick one or more of the following options: organic farming; occupation of leisure times; supplement to family budget; practice of physical exercise; 
environmental concerns; education; taste for agriculture; need; and other. The 'other' option offers the possibility to reveal other motivations. The application form also includes a field for observations and comments.

\section{Descriptive statistics}

For descriptive statistics purposes, applicants were grouped into classes. These classes were built according to the information available in the MNUAG application forms and/or the classes used by the Portuguese national statistics. Age was aggregated in 4 age classes: less than 25 years; 25 to 44 years; 45 to 64 years; 65 years and more. Professions were aggregated according to the classes of the Portuguese classification of occupations in 2010 (INE, 2011a). The characteristics of the MNUAG applicants were compared with the characteristics of the resident population of Vila Nova de Gaia county provided by the 2011 Population Census (INE, 2012), to see if applicants are representative of the overall population or if they represent special groups of this population.

\section{The Logit model}

To relate motivations and characteristics of the MNUAG applicants or potential users we have run a Logit model. In the context, each multiple logistic regression $j$ has a dichotomous outcome $\left(M_{j}=1\right.$, motivation $j$ is referred, and $M_{j}=0$, motivation $j$ is not referred) and $X$ independent variables giving the characteristics of applicants. The logistic regression analysis yields the odds of motivation $j$ being referred in relation to the independent variables:

$$
\hat{p}_{j}=E\left(M_{j}=1 \backslash X\right)=\frac{\exp ^{X+u_{j}}}{1+\exp ^{X+u_{j}}} j=1, \ldots, m \text { motivations }
$$

By using the natural log of the odds of each motivation $j$ as the dependent variable the relationships can be linearized and treated much like multiple linear regression:

$$
\ln \left(\frac{\hat{p}_{j}}{1-\hat{p}_{j}}\right)=X \beta+u_{j}, \hat{L}_{j}=\ln \left(\frac{\hat{p}_{j}}{1-\hat{p}_{j}}\right) \text { being called the logit }
$$


Notice that in (1) and in (2), $u_{j}$ is the residual term associated with motivation $j$.

As $\hat{p}_{j}$ goes from 0 to 1 , the logit goes from $-\infty$ to $+\infty$. The logit is linear in $X$ while the probabilities are not. Regression results can be presented showing the $\beta$ coefficients or equivalently the related 'Odds Ratios'. A positive (negative) coefficient implies the corresponding 'Odds Ratio' being greater (less) than one. That is, if the value of the specific regressor increases (decreases) the odds that motivation $j$ is mentioned increases (decreases).

We have considered as dependent variables the six most frequently mentioned motivations $M 1$ to $M 6$, which are respectively: $M 1$ - 'To supplement family budget'; M2- 'Occupation of leisure times'; M3- 'Access to organic farming'; M4- 'The practice of physical exercise'; M5'Environmental concerns'; and M6- 'Education'.

We have considered as independent variables the characteristics of the MNUAG applicants. In the case of qualitative variables, dummy variables were built for each category. More specifically, CPp1 to Cpp10 are the classes of the Portuguese classification of occupations in 2010 (INE, 2011a): Cpp0- 'Armed forces jobs'; Cpp1- 'Representatives of legislative and executive bodies, officers, directors and executive managers'; Cpp2- 'Experts of intellectual and scientific activities'; Cpp3- 'Technicians of intermediate level'; Cpp4- 'Administrative personnel'; Cpp5- 'Employees of personal, safety, and security services and sellers'; Cpp6'Farmers and skilled workers in agriculture, fisheries and forest'; $C p p 7$ - 'Skilled workers in industry, construction and craftsmen'; Сpp8- 'Plant and machine operators and assemblers'; Срp9- 'Unskilled workers'; Cpp10- 'No profession or unspecified'.

The variable Year 2013 is a dummy variable that separates applications in the year 2013 from applications in the year 2012. It allows checking if late applicants (2013) differ significantly in their motivations from early applicants (2012).

Finally, we have considered dummy variables controlling for parish of residence. The latter are control variables that capture specific parish effects that are not being captured by the other regressors, and have been considered just for the purpose of estimation consistency.

\section{Results and Discussion}


Fig. 2 shows the distribution of applicants per parish of residence. The majority of MNUAG applicants live in the more densely populated parishes of the county. Most of the built UAG are located either in these parishes or in neighboring parishes. Curiously, many UAG under construction or to be constructed are located in less densely populated parishes.

\section{Insert Fig. 2}

MNUAG female applicants have a slightly larger share (53\%) than male applicants (47\%). Applicant's gender distribution is similar to county gender distribution (52\% female and $48 \%$ male).

Fig. 3 characterizes the MNUAG applicants by age group, household size, profession, and job status.

\section{Insert Fig. 3}

The largest share of the MNUAG applicants (90\%) are between 25 and 64 years old, what shows an overrepresentation of this age group when compared with the county population (58\%) (INE, 2016). The age group under age 25 (26\% of the resident population) accounts for only $1 \%$ of the applications, while the age group older than 65 (15\% of the resident population) accounts for $9 \%$ of the applications (INE, 2012).

These figures reveal that most of the applicants belong to the working age population between 25 and 64 years old. The underrepresentation of the younger and older generations in the universe of applicants does not mean necessarily that these generations are not potential users of MNUAG gardens. It might mean that in a household with ascendants and descendants the most likely applicants are the working group members. Nevertheless, the underrepresentation of the older generation is somehow an unexpected result in a country where many people in this age group were born in rural areas and $48 \%$ of the rural farmers are over 65 years (INE, 2011b). 
The average age of the MNUAG applicants is 47 years against 40 years of the 2011 Gaia resident population (INE, 2012).

Most of the MNUAG applicants (84\%) come from households with 2 to 4 members, a figure superior to that of county residents $(75 \%)$. Households with one member represent only $10 \%$ of the applications, and are bellow the corresponding county figure (19\%). Households with 5 or more members account for $6 \%$ of the applicants and of the county residents. (INE, 2012).

More than 1/5 of the MNUAG applicants (21\%) have higher education or leading professional positions, a percentage superior to that of the county residents with higher education $(12,5 \%)$ (INE, 2012). These figures reveal that one important group of potential urban gardeners in Vila Nova de Gaia is a group of highly educated and informed people.

Half of the MNUAG applicants (50\%) are employed and about one third (34\%) unemployed. When comparing these numbers with the corresponding numbers for the resident population in 2011(INE, 2012), respectively $41 \%$ and $9 \%$, one can identify a quite significant representation of the unemployed in the MNUAG applicants. While there is a balanced gender distribution in MNUAG applicants and in the unemployed Gaia resident population (53\% male and $47 \%$ female), $63 \%$ of the MNUAG unemployed applicants are women.

Retirees are $9 \%$ of the applicants, being underrepresented when compared to the retired resident population (19\%). As most of the retirees are over 65 years, discussion of results is similar to that of this age group.

In summary, the main general characteristics of the population applying to MNUAG urban allotment gardens are: a balanced gender distribution; a dominance of the 25 to 64 years old age group; an average age of 47 years; and a dominance of applicants from households with 2 to 4 members. Two important groups of potential users were identified: the unemployed that account for $34 \%$ of the applicants, and the highly educated leading professionals that account for $21 \%$ of the applicants. 
Fig. 4 shows the distribution of the MNUAG applicants' motivations. To supplement family budget (24\%), occupation of leisure times (21\%), and access to organic farming (19\%) are the most frequently mentioned motivations. The practice of physical exercise $(10 \%)$, environmental concerns (14\%), and education (10\%) are also frequently mentioned motivations. Only $2 \%$ of the motivations follow under the 'other' pre-coded option.

\section{Insert Fig. 4}

This diverse range of motivations is consistent with the literature. The three most frequent motivations to apply for a MNUAG plot were to supplement family budget (food security), occupation of leisure times (recreation) and access to organic farming (food safety). According to several authors food production is one of the most important motivations worldwide to join UAG, often as a response to growing concerns about food safety. Many authors also refer economic reasons as a strong motivation. Domene and Sauri (2006) and Guitart et al. (2012) identified 'saving money' as one of the most important reasons to join a UAG.

Similarly, recreation was also found in many studies as a motivation to join UAG. Environmental concerns, the practice of physical exercise and education were less common motivations found in this research but they are also consistent with the literature.

Some motivations referred in the literature were not directly mentioned by the MNUAG applicants. That is the case of health concerns, the development of skills, place attachment, and social interaction, among others. Of all these, the most surprising is social interaction, once it is referred in many studies as one of the most important reasons for engaging in urban allotment gardens, either as an initial or secondary motivation. The most plausible explanation for this fact is the design of the MNUAG application form, since the above motivations were not included in the list of options presented to the applicants. Although the opportunity to add other motivations under the 'other' option was offered, respondents tend to choose what is on the list. However, while not specifically stated, health concerns can be implicit in the motivation 'access to organic farming' and the motivation 'practice of physical 
exercise'. Similarly, the 'occupation of leisure times' can be associated to social interaction, and 'education' to the development of skills.

\section{The influence of characteristics of MNUAG potential users on their motivations}

Table 1 presents estimation results in terms of 'Odd Ratios'. The 'Odd Ratios' of parish dummies and of the constant term are not stated. Non-significant coefficients are also not stated. The Stata complete output is available under request.

\section{Insert Table. 1}

The Logit model results show that the characteristics of MNUAG applicants influence their motivations. Follows a summary, by motivation, of how the characteristics increase or decrease the frequency (odds) of the motivation being mentioned by the applicants. A summary by characteristic can be found in Appendix 1 .

The motivation M1- 'To supplement family budget' (food security) is significantly more frequently mentioned by Cpp9- 'Unskilled workers', unemployed, applicants without a formal profession, and applicants with larger families. It is significantly less frequently mentioned by Cpp1- 'Representatives of legislative and executive bodies, officers, directors and executive managers', Cpp2 -'Experts of intellectual and scientific activities', and Cpp10'No profession or unspecified'.

The motivation M2- 'Occupation of leisure time' is significantly more frequently mentioned by older applicants. It is significantly less frequently mentioned by women, Cpp1'Representatives of legislative and executive bodies, officers, directors and executive managers', Cpp6- 'Farmers and skilled workers in agriculture, fisheries and forest', and applicants with large families.

The motivation M3- 'Access to organic farming' is significantly more frequently mentioned by Cpp2- 'Experts of intellectual and scientific activities'. It is significantly less frequently mentioned by Cpp8- 'Plant and machine operators and assemblers', applicants with large families, and late applicants. 
The motivation M4- 'The practice of physical exercise' is significantly more frequently mentioned by Cpp3- 'Technicians of intermediate level' and Cpp4- 'Administrative personnel'. It is significantly less frequently mentioned by applicants with large families and late applicants.

The motivation M5- 'Environmental concerns' is significantly more frequently mentioned by Cpp2- 'Experts of intellectual and scientific activities', Cpp3- 'Technicians of intermediate level', Cpp4- 'Administrative personnel', and Cpp6- 'Farmers and skilled workers in agriculture, fisheries and forest'. It is significantly less frequently mentioned by older applicants, unemployed, applicants with larger families, and late applicants.

The motivation M6- 'Education' is significantly more frequently mentioned by Cpp2'Experts of intellectual and scientific activities', Cpp3- 'Technicians of intermediate level', and students. It is significantly less frequently mentioned by older applicants and applicants with 'Other' job status.

Results of the descriptive statistics revealed two relevant groups of applicants to the MNUAG: the unemployed and the highly educated leading professionals (Cpp1 and Cpp2).

The unemployed, who account for $34 \%$ of the MNUAG applicants, mention more frequently motivation M1- "To supplement family budget" and less frequently motivations M3 “Access to organic farming" and M5 -"Environmental concerns". Unemployed seem to apply to UAG because they see it as a way of overcoming their economic situation through the generation of some income. Food security is the fundamental motivation of this group, which is not so much concerned with food safety and environmental issues.

Low-income applicants (unskilled workers, applicants without a formal profession, and applicants with larger families) also mention more frequently motivation M1. The Logit model results show no other frequently mentioned motivation in groups where the food security motivation is significantly preferred.

The group of highly educated leading professionals accounts for $21 \%$ of the MNUAG applicants. This group mentions less frequently motivation M1- 'To supplement family budget'. As opposed to the unemployed and low-income applicants, food security is not a 
main motivation to engage in urban gardening for this group. Their more frequently mentioned motivations are food safety, environmental concerns, and education. Their significant motivations match some of the motivations described by Scheromm (2015) for the hedonist gardener and militant gardener.

Age increases the odds of motivation M2- 'Occupation of leisure times' and decreases the odds of motivations M3- 'Access to organic farming', M5- 'Environmental concerns', and M6- 'Education' being mentioned. This suggests that 'militant gardening' is more likely to occur among the younger and more educated applicants.

\section{Conclusions}

Demand for UAG has been growing very significantly in Portugal. However, very little is known about the characteristics of the population behind this demand, their motivations, and how the characteristics affect the motivations.

To answer these questions, we have conducted a case-study research based on secondary data provided by the application forms to the Municipal Network of Urban Allotment Gardens (MNUAG) of Vila Nova de Gaia submitted in period 2012-2013.

The population of applicants to the MNUAG is quite diverse. It has a balanced gender distribution and an average age of 47 years. Most of the applicants are between 25 and 64 years old, and belong to households with 2 to 4 members. $34 \%$ of the applicants are unemployed and $21 \%$ are highly educated leading professionals.

To supplement the family budget (food security), occupation of leisure times (recreation), and access to organic farming (food safety) are the most mentioned motivations to apply for a MNUAG plot, followed by environmental concerns, the practice of physical exercise (health concerns), and education.

Characteristics affect motivations. The less favored applicants (unemployed, unskilled workers, applicants without a formal profession, and applicants with larger families) mention more frequently the food security motivation to apply to MNUAG plots. There is no other 
frequently mentioned motivation in groups where the food security motivation is significantly preferred.

Applicants from upper and intermediate professions mention more frequently food security, health concerns, environmental concerns, recreation, and education motivations.

Unlike the less favored applicants, these applicants don't have as main objective for their application to the MNUAG the production of food.

This study can have future implications on the planning of the MNUAG. Results show that unemployed account for about one third of the MNUAG applicants. This finding should have consequences on the location and plot size of the MNUAG allotment gardens. To provide food for a household and allow the production of some surplus to sell, MNUAG plot size should be larger than the actual sizes ( 35 to $70 \mathrm{~m} 2$ ). According to LIPOR (2016), plots should have $100 \mathrm{~m} 2$ to meet the above subsistence goals. Allotment gardens should also be easily accessible, as the unemployed population might have difficulties of accessing it by car. The current MNUAG pattern, a network of small UAG distributed by all the Gaia territory in close vicinity to urbanizations, favors access. However, the integration of the MNUAG in a soft mobility network and in the public transportation network would facilitate access by bike and/or bus, stimulating at the same time recreation and good environmental practices.

Increase in the plot size will decrease the number of plots by UAG and decrease the already short offer of plots in face of the demand. In June of 2015, the number of MNUAG applicants had increased to 1251 , with 978 being on the waiting list. Just to meet the existing demand of the less favored population (unemployed and low income residents), the number of MNUAG plots must increase.

Moreover, while the MNUAG should continue to select the less favored applicants, it should also meet the demand of those whose motivations are food safety, recreation, education, and environmental concerns. The later represent a new paradigm of urban gardeners, less utilitarian and more environmental friendly, that is desirable to stimulate. Also, the coexistence of different social groups in MNUAG gardens is fundamental to stimulate social cohesion, and avoid segregation and stigmatization. 
So we suggest that the municipality reinforces its small UAG structure in the close vicinity of housing developments, but add to the network one or two productive parks, similar to the Lisboa Horticultural Parks. Productive parks can lodge a large number of plots with different sizes, and host public recreation areas and a market area to sell gardeners surplus production. They should also be served by a soft mobility and public transportation network to facilitate low cost and environment friendly access.

Study findings should have broader policy implications. The fact that 'to supplement the family budget' is the most important motivation for MNUAG applicants, namely for the unemployed and low-income groups, should not be ignored by European and National policies addressing issues such as unemployment and food security. The same applies to policies addressing issues such as food safety, environmental problems and recreation. UAG can also be a useful instrument for policies pursuing social cohesion, as they have the capability to bring together groups that usually live apart in our society, a benefit often mentioned in the literature.

\section{Future research}

This case-study research allowed us to identify the main characteristics of the population applying to the MNUAG, to identify its motivations, and to determine how motivations to apply to a MNUAG garden are influenced by the characteristics of the applicants. To generalize these findings to the Portuguese universe of potential urban gardeners we will need to expand research to other case studies.

The use of secondary data in this research (data of the MNUAG application forms submitted in the period 2012-2013) didn't allow us to explore some characteristics and motivations of the MNUAG potential users. It would have been interesting to know who were the potential users behind each application and their characteristics, as that information would give us a more complete portrait of the universe of potential users and not only the portrait of the applicant itself.

Follow-up of this research can include the realization of interviews to the actual MNUAG gardeners. That would allow us to identify selection criteria, to expand knowledge on the 
characteristics and initial motivations of selected applicants, and to identify secondary motivations (motivations arising from the experience itself).

\section{Acknowledgements}

The authors wish to acknowledge the municipality of Vila Nova de Gaia for all of the information and documentation that made the elaboration of this paper possible.

\section{Appendix 1}

Summary, by characteristic, of Logit model results.

The 'Female' gender decreases the odds of motivation M2- 'Occupation of leisure times' being mentioned.

'Age' increases the odds of motivation M2- 'Occupation of leisure times' and decreases the odds of motivations M3- 'Access to organic farming', M5- 'Environmental concerns', and M6- 'Education' being mentioned.

Occupation Cpp1- 'Representatives of legislative and executive bodies, officers, directors and executive managers' decreases the odds of motivations M1- 'To supplement family budget' and M2 - 'Occupation of leisure times' being mentioned.

Occupation Cpp2- 'Experts of intellectual and scientific activities' increases the odds of motivations M3- 'Access to organic farming', M5- 'Environmental concerns', and M6'Education', and decreases the odds of motivation M1- 'To supplement family budget' being mentioned.

Occupation Cpp3- 'Technicians of intermediate level' increases the odds of motivations M4'The practice of physical exercise', M5- 'Environmental concerns', and M6- 'Education' being mentioned.

Occupation Cpp4- 'Administrative personnel' increase the odds of motivations M4- 'The practice of physical exercise' and M5- 'Environmental concerns' being mentioned. 
Occupation Cpp6- 'Farmers and skilled workers in agriculture, fisheries and forest' increases the odds M5- 'Environmental concerns' and decreases the odds M2- 'Occupation of leisure times' being mentioned.

Occupation Cpp8- 'Plant and machine operators and assemblers' decrease the odds of motivation M3- 'Access to organic farming' being mentioned.

Occupation Cpp9- 'Unskilled workers' increase the odds of motivation M1- 'To supplement family budget'.

Occupation Cpp10- 'No profession or unspecified' decreases the odds of M1- 'To supplement family budget' being mentioned.

Job status 'Unemployed' increases the odds of motivation M1 - 'To supplement family budget' and decreases the odds of motivations M3- 'Access to organic farming' and M5'Environmental concerns' being mentioned.

Job status 'Student' increases the odds of motivation M6- 'Education' being mentioned.

Job status 'Other' (people at home such as housewives) increases the odds of motivation M1'To supplement family budget' and decreases the odds of M6- 'Education' being mentioned.

Family size increases the odds of motivation M1- 'To supplement family budget' and decreases the odds of motivations M2- 'Occupation of leisure times', M3- 'Access to organic farming', M4- 'The practice of physical exercise', and M5- 'Environmental concerns' being mentioned.

Year 2013 decreases the odds of M3- 'Access to organic farming', M4- 'The practice of physical exercise', and M5- 'Environmental concerns' being mentioned.

\section{References}


Alaimo, K., Packnett, E., Miles, R., Kruger, D., 2008. Fruit and vegetable intake among urban community gardeners. Journal of Nutrition Education \& Behaviour, 40:2, pp. 94-101.

Armstrong, D., 2000. A survey of community gardens in upstate New York: implications for health promotion and community development. Health \& Place, 6, pp. 319-327.

Augustina, I., Beilin, R., 2011. Community Gardens: Space for Interactions and Adaptations. ASEAN Conference on Environment-Behaviour Studies (AcE-Bs), Savoy Homann Bidakara Hotel, 15-17 June 2011, Bandung, Indonesia. Procedia - Social and Behavioral Sciences, 36, pp 439-448.

Baker, L., 2004. Tending cultural landscapes and food citizenship in Toronto's community gardens. Geographical Review, 94:3, pp. 305-325.

Bendt, P., Barthel, S., Colding, J. 2012. Civic greening and environmental learning in publicaccess community gardens in Berlin. Landscape and Urban Planning, 109:1, pp. 18-30. Special Issue: Urban Ecosystem Services.

Blair, D., Giesecke, C., Sherman, S., 1991. A dietary, social and economic evaluation of the Philadelphia urban gardening project. The Journal of Nutrition Education, 23:4, pp. 161-167.

Clayton, S., 2007. Domesticated nature: Motivations for gardening and perceptions of environmental impact. Journal of Environmental Psychology, 27:3, pp. 215-224.

CML (Câmara Municipal de Lisboa), [website], www.cm-lisboa.pt/viver/ambiente/parqueshorticolas-municipais, accessed 5 May 2016.

Corrigan, N., 2011a. Community Gardening, Motivation and Health Benefits. A thesis presented towards the degree of Bachelor of Science in Human Nutrition and Dietetics BSc (Hum Nut) at The University of Dublin, Trinity College and Dublin Institute of Technology 2011. 
Corrigan, M.P., 2011b. Growing what you eat: developing community gardens in Baltimore, Maryland. Applied Geography, 31:4, pp. 1232-1241. Local Food Systems and the Applied Geography of Food.

Domene, E., Saurí, D. 2006. Urbanization and class-produced natures: Vegetable gardens in the Barcelona Metropolitan Region. Geoforum, 38:2, pp. 287-298.

European Environmental Agency, 2015. Revision of World Population Prospects. http://esa.un.org/unpd/wpp/DVD/

Glover, T., 2003. The story of the Queen Anne Memorial Garden: resisting a dominant cultural narrative. Journal of Leisure Research, 35:2, pp.190-212.

Golden, S., 2013. Urban Agriculture Impacts: Social, Health, and Economic: A Literature Review. University of California. Agriculture and Natural Resources. 22 p.

Gonçalves, R., 2014. Hortas Urbanas. Estudo do Caso de Lisboa. Dissertação para a obtenção do Grau de Mestre em Engenharia Agronómica. Universidade de Lisboa.130 p.

Guitart, D., Pickering, C., Byrne, J., 2012. Past results and future directions in urban community gardens research. Urban Forestry \& Urban Greening, 11:4, pp. 364-373.

Henryks, J., 2011. Changing the menu: rediscovering ingredients for a successful volunteer experience in school kitchen gardens. Local Environment 16:6, pp 569-583. DOI: $10.1080 / 13549839.2011 .577058$

Holland, L., 2011. Diversity and connections in community gardens: a contribution to local sustainability. Local Environment 9:3, pp. 285-305, DOI: 10.1080/1354983042000219388

Ilyniak S. \& Khuns, J., 2013. Perspectives on Urban Agriculture's Social Environments in Wets-End Toronto: opportunities, challenges and broader urban social context. 38 p.

INE, 2011a. Instituto Nacional de Estatística (Statistics Portugal). Classificação Portuguesa das Profissões: 2010. 
INE, 2011b. Instituto Nacional de Estatística (Statistics Portugal). Recenceamento Agrícola 2009.

INE, 2012. Instituto Nacional de Estatística (Statistics Portugal). Censos 2011.

Irvine, S., Johnson, L., Peters, K., 1999. Community gardens and sustainable land use planning: a case-study of the Alex Wilson Community Garden. Local Environment 4:1, pp. 33-46, DOI: $10.1080 / 13549839908725579$

Kaplan, R., 1973. Some psychological benefits of gardening. Environment \& Behaviour 5:2, pp.145-162.

Kaplan, R., \& Kaplan, S. 1990. Restorative experience; The healing power of nearby nature. In M. Francis, \& R.T. Hester Jr (Eds), The meaning of gardens. Cambridge, MA: MIT Press. ISBN: 9780262560610,293 p.

Kelly, M. 2012. Cultivating respect for difference: Exploring the enactment of community at HOPE Garden in Parkdale, Toronto. The University of Western Ontario. Electronic Thesis and Dissertation Repository. Paper 636.

Kingsley, J., Townsend, M., Henderson-Wilson, C., 2009. Cultivating health and wellbeing: members' perceptions of the health benefits of a Port Melbourne community garden. Leisure Studies 28:2, pp. 207-219, DOI: 10.1080/02614360902769894

LIPOR, 'Horta à Porta', [website], www.lipor.pt/pt/educacao-ambiental/horta-daformiga/agricultura-biologica/horta-a-porta, accessed 5 May 2016

Martinho da Silva, I. 2014. Urban Agriculture in Vila Nova de Gaia: The Nurturing Symbiosis. Journal of Landscape Architecture 9:2, pp. 42-49.

Municipio de Vila Nova de Gaia (MVNG), 2013. Normas de Utilização das Hortas Urbanas, unpublished administrative document. 
Meenar, M., Hoover, B., 2012. Community food security via urban agriculture:

Understanding people, place, economy, and accessibility from a food justice perspective. Journal of Agriculture, Food Systems, and Community Development

Scheromm, P., 2015. Motivations and practices of gardeners in urban collective gardens: The case of Montpellier. Urban Forest \& Urban Greening 14 pp. 735-742. DOI:

10.1016/j.ufug.2015.02.007

Silva, V., 2013. O projeto da Rede Municipal de Hortas Urbanas de Vila Nova de Gaia. Gaiurb: Urbanismo e Habitação, EM (not published).

Teig, E., Amulya, J., Bardwell, L., Buchenau, M., Marshall, J., Jill, S., 2009. Collective efficacy in Denver, Colorado: strengthening neighbourhoods and health through community gardens. Health \& Place, 15:4, pp. 1115-1122. DOI:10.1016/j.healthplace.2009.06.003

United Nations. 2014. Revision World Urbanization Prospects. http://esa.un.org/unpd/wup/Highlights/WUP2014-Highlights.pdf

Van den Berg, A.W., Marijke, W., de Vries, S., 2010. Allotment gardening and health: a comparative survey among allotment gardeners and their neighbors without an allotment. Environmental Health, 9:74, 12 p. DOI:10.1186/1476-069X-9-74.

Yin, R. K. 2013. Case Study Research: Design and Methods. Applied Social Research Methods Series, 5: 219. 
Fig. 1. (a) Northern Portugal. (b) The municipality of Vila Nova de Gaia in Northern Portugal and Porto Metropolitan Area. (c) The municipality of Vila Nova de Gaia and its parishes.

Fig. 2. Applications to MNUAG gardens per parish of residence.

Fig. 3. Characteristics of the MNUAG applicants.

Fig. 4: Motivations of MNUAG applicants. 


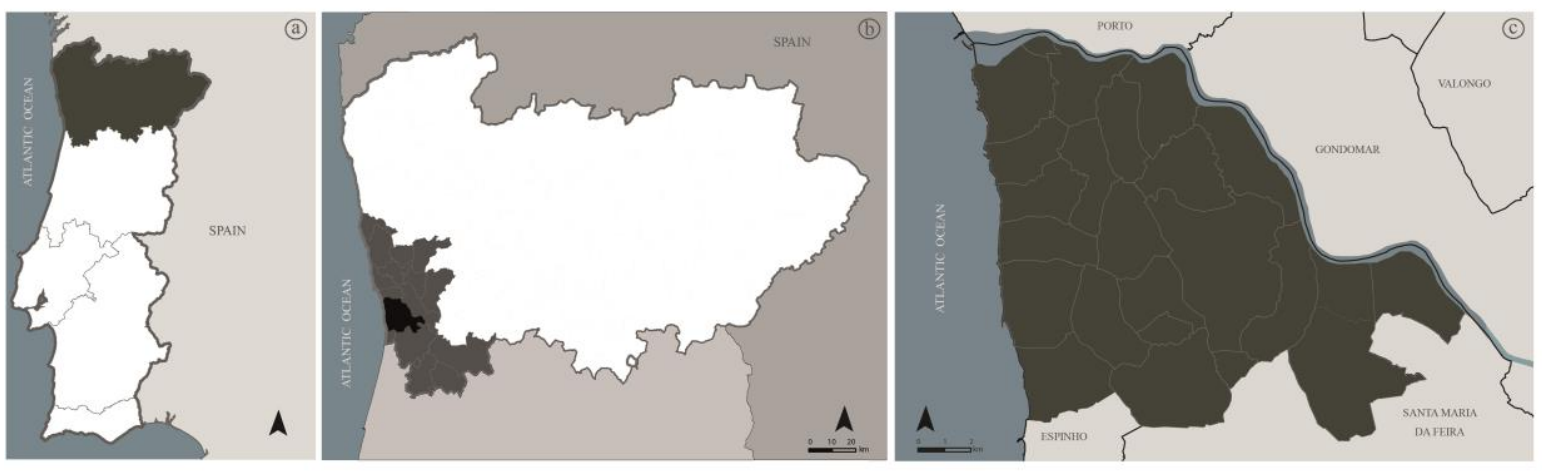

Fig. 1. (a) Northern Portugal. (b) The municipality of Vila Nova de Gaia in Northern Portugal and Porto Metropolitan Area. (c) The municipality of Vila Nova de Gaia and its parishes. 


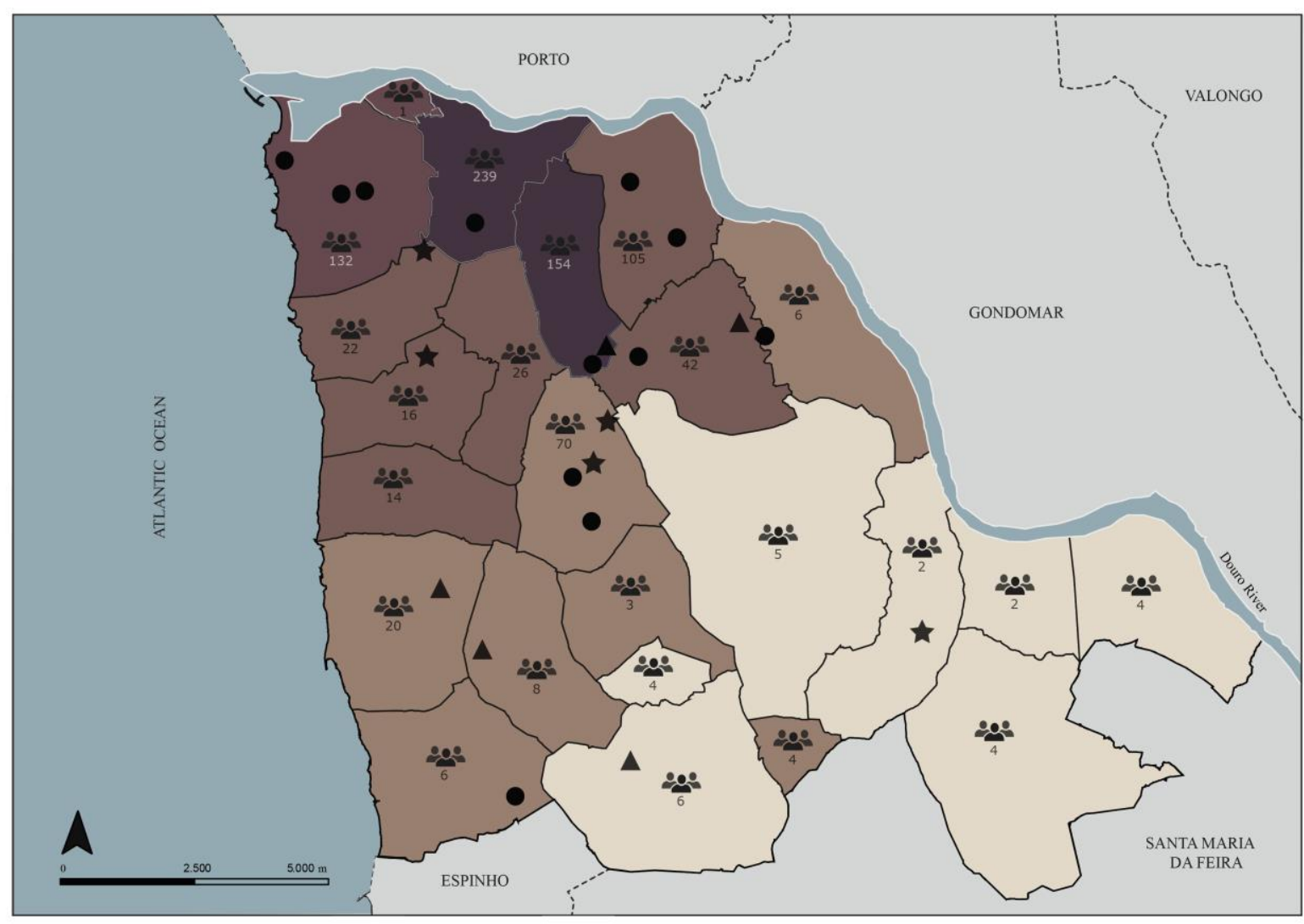

LEGEND:

1. Localization of MNUAG garden

2. Population áensity (inhabitants $/ \mathrm{km} 2$ ):

Built

Under construction

To be constructed

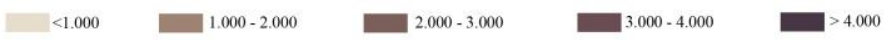

3. Number of applications to MNUAG: 200

Fig. 2. Applications to MNUAG gardens per parish of residence. 

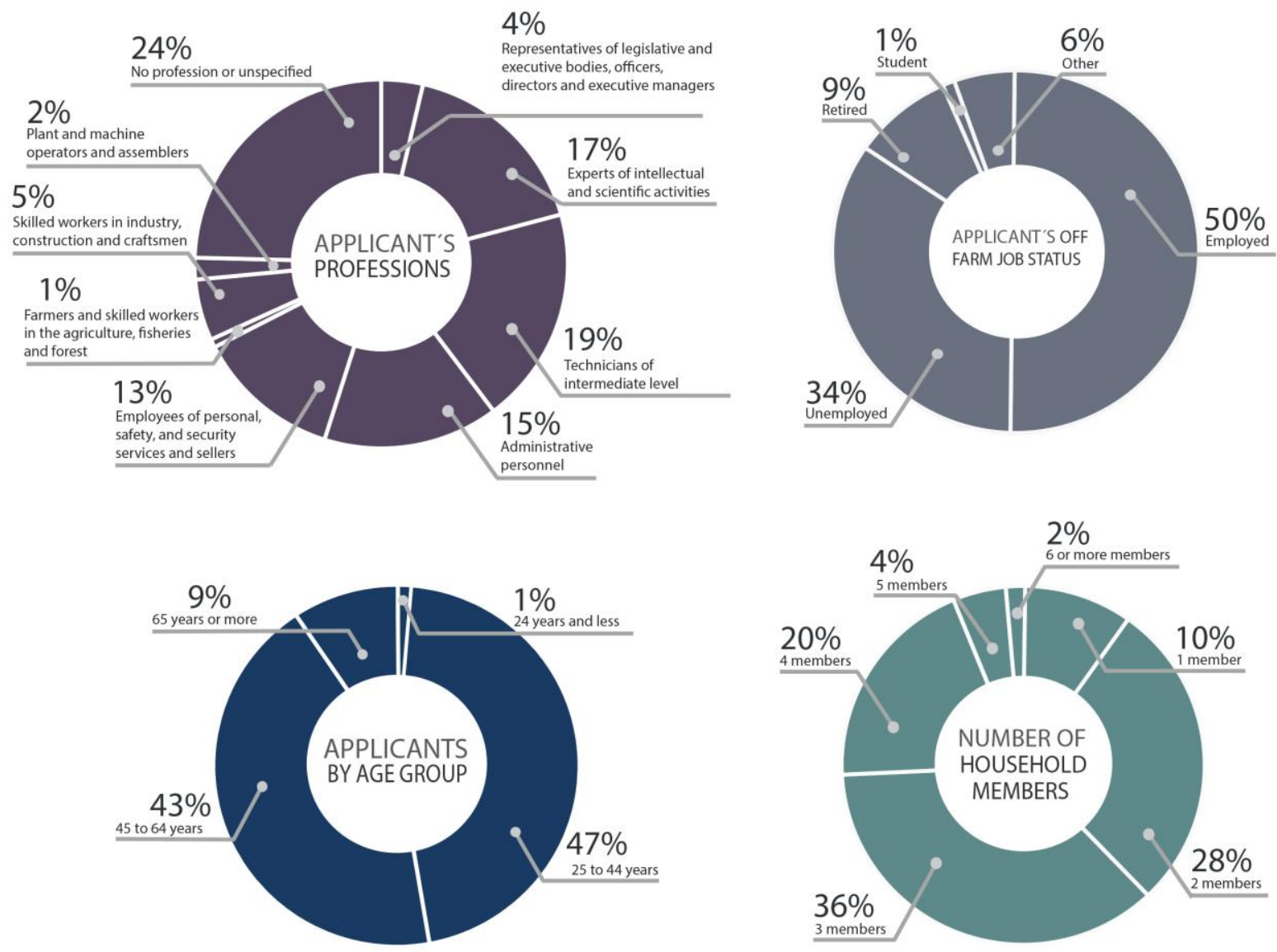

Fig. 3. Characteristics of the MNUAG applicants. 


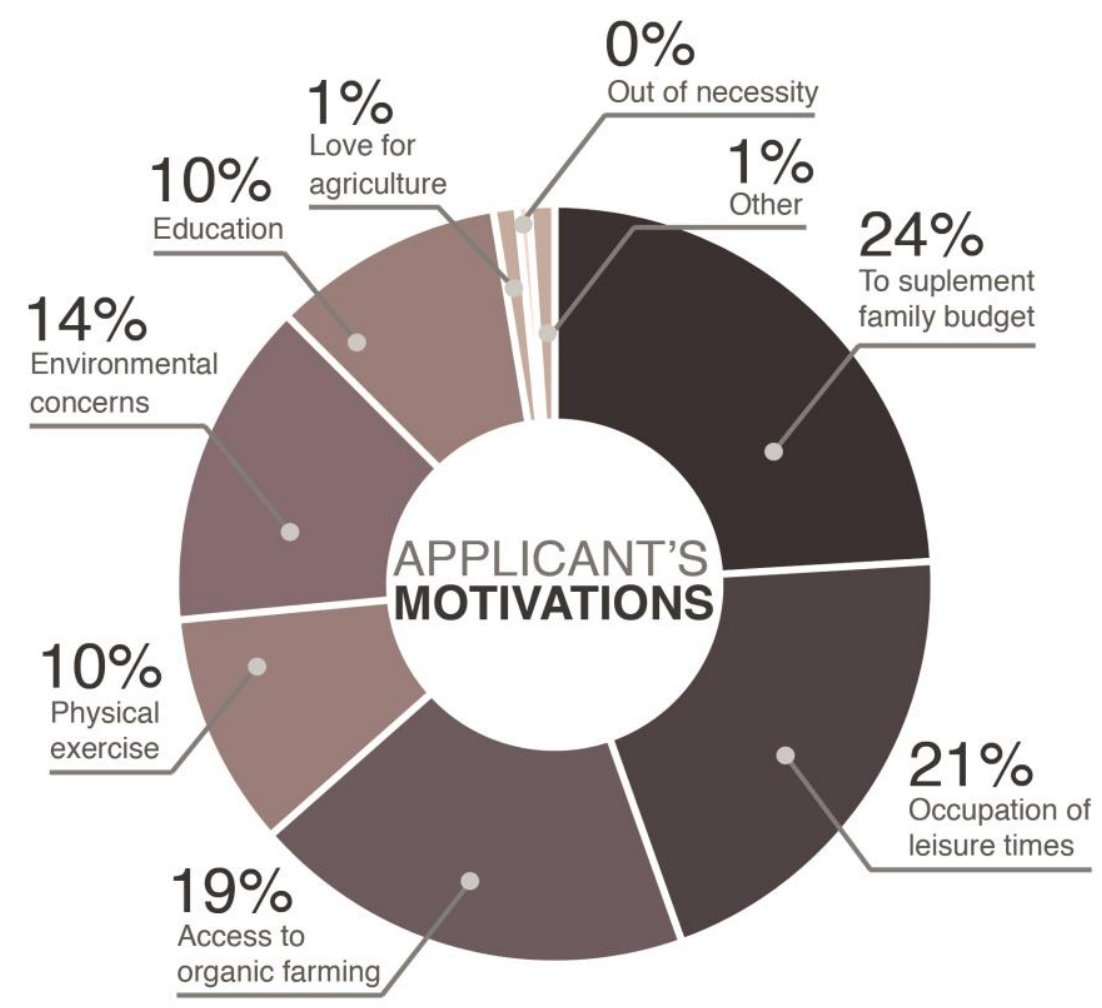

Fig. 4: Motivations of MNUAG applicants. 
Table 1. Logit model results. 


\begin{tabular}{|c|c|c|c|c|c|c|}
\hline \multicolumn{7}{|c|}{ Odds Ratio (level of significance $1 \% *, 5 \% * *$, and $10 \% * * *$ ) } \\
\hline & M1 & M2 & M3 & M4 & M5 & M6 \\
\hline Female & & $0.7534092 * * *$ & & & & \\
\hline Age & & $1.022803 *$ & $0.9660521^{*}$ & & $0.9797782 *$ & $0.9703574 *$ \\
\hline Cpp1 & $0.4278161 * * *$ & $0.4417188 * * *$ & & & & \\
\hline Cpp2 & $0.3417481^{*}$ & & $1.78016^{* * *}$ & & $2.785636^{*}$ & $2.314104^{*}$ \\
\hline Cpp3 & & & & $1.74771 * * *$ & $1.807817 * *$ & $1.782156^{* *}$ \\
\hline Cpp4 & & & & $1.87883^{* *}$ & $2.099598 *$ & \\
\hline Cpp6 & & $0.2433408 * * *$ & & & $9.777565 * * *$ & \\
\hline \multicolumn{7}{|l|}{ Cpp7 } \\
\hline Cpp8 & & & $0.3190815^{* * *}$ & & & \\
\hline Cpp9 & $5.513289 * * *$ & & & & & \\
\hline Cpp10 & $0.4565627^{* *}$ & & & & & \\
\hline Unemployed & $3.404408^{*}$ & & $0.6500982 * * *$ & & $0.6597856^{* *}$ & \\
\hline \multicolumn{7}{|l|}{ Retired } \\
\hline Student & & & & & & $3.094365 * * *$ \\
\hline Other & $2.703261 * *$ & & & & & $0.3070427^{*}$ \\
\hline Family size & $1.279552 *$ & $0.8293133^{*}$ & $0.8732915^{* *}$ & $0.869266 * *$ & $0.8296877^{*}$ & \\
\hline Year 2013 & & & $0.715907 * *$ & $0.72505^{* * *}$ & $0.5681917^{*}$ & \\
\hline Log pseudolikelihood & -433.1046 & -534.48052 & -535.71442 & -521.8675 & -529.21044 & -505.79868 \\
\hline Number of obs & 873 & 873 & 873 & 873 & 873 & 873 \\
\hline Wald chi2(32) & 79.61 & 60.62 & 87.01 & 47.23 & 122.21 & 70.29 \\
\hline Prob > chi2 & 0.0000 & 0.0008 & 0.0000 & 0.0236 & 0.0000 & 0.0000 \\
\hline Pseudo R2 & 0.0898 & 0.0579 & 0.0868 & 0.0446 & 0.1169 & 0.0714 \\
\hline
\end{tabular}

Table 1. Logit model results. 